\title{
Alternatives for erroneous finger probe pulse oximetry in systemic sclerosis patients during COVID-19 pandemic
}

\author{
Yashdeep Singh Pathania ${ }^{1}$ (D) \\ Received: 9 September 2021 / Accepted: 12 October 2021 / Published online: 15 October 2021 \\ (c) The Author(s), under exclusive licence to Springer-Verlag GmbH Germany, part of Springer Nature 2021
}

Keywords Pulse oximetry · Systemic sclerosis · COVID-19 · Accuracy

\section{Dear Editor,}

The ongoing corona virus disease 2019 (COVID-19) pandemic has posed a serious threat to everybody. Moreover, it has posed even more serious challenge in managing patients with concomitant co-morbidities. Patients with autoimmune connective tissue diseases showed a higher prevalence of symptomatic COVID-19 [1]. Systemic sclerosis is one of the most severe autoimmune connective tissue diseases (ACTD) characterized by fibrosis of skin and internal organs (multisystem), vasculopathy and dysregulation of immune system. COVID-19 and systemic sclerosis share pathological alterations such as interstitial lung involvement that may evolve to lung fibrosis. In a survey by Ferri et al. [2] found, COVID-19 was more prevalent in patients with symptomatic systemic sclerosis patients with high prevalence of death.

Oxygen saturation monitoring in COVID-19 patients is an important tool for prognosis and titration of oxygen therapy. Oxygen saturation is usually measured through a finger probe pulse oximetry in COVID-19 patients. Pulse oximetry is an useful, readily available and non-invasive tool of measuring oxygen saturation. It uses light sensors containing two light sources of different wavelengths, that are absorbed by haemoglobin (both oxy and deoxy forms) and transmitted through tissues to a photodetector. Any discrepancy in the light transmission caused either by vascular abnormality of the fingers or anatomical change may lead to inaccurate or absence of reading in the pulse oximeter. Systemic sclerosis patients with COVID-19 pose a serious challenge for monitoring of oxygen saturation through finger probe pulse oximetry due to sclerodactyly, microvascular damage and

Yashdeep Singh Pathania

yashdeepsinghpathania@gmail.com

1 Dermatology, Venereology and Leprology, Derma Care, V.P.O Rey District, Kangra, Himachal Pradesh 176058, India digital ulceration. Finger probe pulse oximetry usually gives false low or even absent values in systemic sclerosis patients [3]. Therefore, pulse oximetry results in systemic sclerosis patients should be interpreted with wariness.

Akdogan et al. [4] investigated the effect of nailfold capillaroscopic patterns on pulse oximetry measurements in systemic sclerosis patients. Oxygen saturation measurements were performed from 2nd to 5th fingers in both hands with a finger probe pulse oximetry. The oxygen saturation could not be measured in $37.7 \%$ systemic sclerosis patients and there was $>4 \%$ difference between the minimum and maximum oxygen saturation measurements. Authors suggested assessment of the highest measured oxygen saturation values among the fingers of a patient which may be more suitable in practice [4]. Although, authors did not detect any effect of capillaroscopic patterns on mean $\mathrm{SpO} 2$ values, possibly due to non-uniform distribution of vasculopathic damage. Nailfold capillaroscopy may aid in finding early, active or late patterns of vascular damage. It is likely that finding of early or very minimal vascular abnormality would corroborate with highest $\mathrm{SpO} 2$ measurement as compared to late pattern, thus it might be speculated to augment a better accuracy for oximetry.

To decrease the error values on finger pulse oximetry in systemic sclerosis patients, a closer examination of fingers must be undertaken. Finger with no sclerodactyly or digital ulceration should be chosen for oximetry. Nail-fold capillaroscopy may aid in the selection of the finger for pulse oximetry. A finger with no obvious sclerodactyly clinically may be confirmed with normal capillaroscopic pattern for reliable oximetry findings. However, if all the fingers are involved due to sclerosis, then it becomes a much bigger challenge to manage. There has been a successful use of ear probe instead of a finger probe for oximetry in a systemic sclerosis patient [3]. There is availability of newer pulse oximeters using an upgraded algorithms and are said 
to be resistant to hypoperfusion and motion. Therefore, their role in systemic sclerosis can be explored [5]. A prospective single centre study of 40 intensive care unit patients, found readings from oesophageal probe were more consistent with arterial oxygen saturation than readings from surface pulse oximetry [6]. In another study of 11 healthy volunteers using forehead oximeter probe concluded that forehead provides an excellent alternative site to monitor $\mathrm{SpO} 2$ and the application of elastic tensioning headband significantly reduced reading errors due to the posture [7]. Therefore, oesophageal and forehead oximeter probes can also be utilized in systemic sclerosis patients with COVID-19 for oxygen saturation measurements $[6,7]$.

Oxygen saturation measurements is an important investigational modality in COVID-19 management. Any discrepancy in the oxygen saturation readings may affect the management. Patients of systemic sclerosis may have oxygen saturation on the lower side due to interstitial lung involvement by the disease. Concomitant COVID-19 in these patients is a dangerous scenario and the monitoring of oxygen saturation in these patients has to be more frequent and critically analysed. The selection of uninvolved fingers is prudent for pulse oximetry in these patients for accurate measurements. However, ear lobe, forehead or oesophageal oximetry may be utilized for oxygen saturation measurements in systemic sclerosis patients with COVID-19 where diffuse involvement of all fingers is present.

Author contribution YSP prepared and finalised the manuscript.

Funding None.

Data availability No new data were generated or analysed in support of this research.

\section{Declarations}

Conflict of interest The author declare they have no conflict of interest.

\section{References}

1. Ferri C, Giuggioli D, Raimondo V, L'Andolina M, Tavoni A, Cecchetti R, Guiducci S, Ursini F, Caminiti M, Varcasia G, Gigliotti P, Pellegrini R, Olivo D, Colaci M, Murdaca G, Brittelli R, Mariano GP, Spinella A, Bellando-Randone S, Aiello V, Bilia S, Giannini D, Ferrari T, Caminiti R, Brusi V, Meliconi R, Fallahi P, Antonelli A; COVID-19 \& ASD Italian Study Group (2020) COVID-19 and rheumatic autoimmune systemic diseases: report of a large Italian patients series. Clin Rheumatol 39:3195-3204

2. Ferri C, Giuggioli D, Raimondo V, Dagna L, Riccieri V, Zanatta E, Guiducci S, Tavoni A, Foti R, Cuomo G, De Angelis R, Cozzi F, Murdaca G, Cavazzana I, Romeo N, Codullo V, Ingegnoli F, Pellegrini R, Varcasia G, Rossa AD, De Santis M, Abignano G, Colaci M, Caminiti M, L'Andolina M, Lubrano E, Spinella A, Lumetti F, De Luca G, Bellando-Randone S, Visalli E, Bilia S, Giannini D, Masini F, Pellegrino G, Pigatto E, Generali E, Dall'Ara F, Mariano GP, Barsotti S, Pettiti G, Zanframundo G, Brittelli R, Aiello V, Scorpiniti D, Ferrari T, Caminiti R, Campochiaro C, D'Angelo S, Iannone F, Matucci-Cerinic M, Doria A, Miccoli M, Fallahi P, Antonelli A; COVID-19 \& Autoimmune Systemic Diseases Italian Study Group (2021) COVID-19 and systemic sclerosis: clinicopathological implications from Italian nationwide survey study. Lancet Rheumatol 3:e166-e168. https:// doi.org/10.1016/S2665-9913(21)00007-2

3. Garg R (2008) Pulse oximetry in scleroderma patients: concerns. Acta Anaesthesiol Scand 52:1303-1304

4. Akdogan A, Kilic L, Dogan I, Karadag O, Bilgen SA, Kiraz S, Ertenli I (2015) Effect of capillaroscopic patterns on the pulse oximetry measurements in systemic sclerosis patients. Microvasc Res 98:183-186

5. Nishiyama T (2006) Pulse oximeters demonstrate different responses during hypothermia and changes in perfusion. Can J Anaesth 53:136-138

6. Vicenzi MN, Gombotz H, Krenn H, Dorn C, Rehak P (2000) Transesophageal versus surface pulse oximetry in intensive care unit patients. Crit Care Med 28:2268-2270. https://doi.org/10. 1097/00003246-200007000-00014

7. Agashe G, Coakley J, Mannheimer PD (2006) Forehead pulse oximetry: headband use helps alleviate false low readings likely related to venous pulsation artifact. Anesthesiology 105:1111-1116

Publisher's Note Springer Nature remains neutral with regard to jurisdictional claims in published maps and institutional affiliations. 